\title{
Improvement of quality of oocytes collected in the autumn by enhanced removal of impaired follicles from previously heat-stressed cows
}

\author{
Z. Roth ${ }^{1}$, A. Arav², A. Bor ${ }^{2}$, Y. Zeron ${ }^{2}$, R. Braw-Tal ${ }^{2}$ \\ and D. Wolfenson ${ }^{1 *}$ \\ ${ }^{1}$ Department of Animal Science, Faculty of Agricultural, Food and Environmental Quality \\ Sciences, The Hebrew University of Jerusalem, Rehovot 76100, Israel; and ${ }^{2}$ Institute of \\ Animal Sciences, Agricultural Research Organization, Bet Dagan 50250, Israel
}

The fertility of dairy cows decreases during the summer and remains low during the cooler autumn although the animals are no longer under heat stress. The aim of this study was to characterize a delayed effect of summer heat stress on oocyte quality in the autumn and to improve oocyte quality by enhanced removal of follicles damaged during the previous summer. Lactating cows $(n=16)$ were subjected to heat stress during the summer. In autumn, ovarian follicles (3-7 $\mathrm{mm}$ in diameter) were aspirated by an ultrasound-guided procedure during four consecutive oestrous cycles. Follicles were aspirated from control cows on day 4 and from treated cows on days 4, 7, 11 and 15 of each oestrous cycle. All cows received $\mathrm{PGF}_{2 \alpha}$ and $\mathrm{GnRH}$ injections on days 19 and 21, respectively, and maintained cyclicity, as indicated by plasma progesterone concentrations. On day 4 of each cycle, the oocytes recovered were examined morphologically, matured and activated in vitro, and cultured for 8 days. In cycle 1 (early October) both groups showed low percentages of grade 1 oocytes, cleavage, four- and eight-cell embryos, morulae and parthenogenetic blastocysts. Subsequently, the number of grade 1 oocytes increased earlier (cycle 2) in treated than in control cows (cycle $3 ; \boldsymbol{P}<\mathbf{0 . 0 5})$. The cleavage rate in the control group remained relatively low throughout (32-58\%), whereas in the treated group it increased from $40 \%$ (cycle 1) to $75 \%$ (cycles 3 and $4 ; P<0.05$ ). The number at each stage of embryo development increased slightly but remained low throughout in the control group, whereas in the treated group significant $(P<0.05)$ increases of all stages were observed in cycles 3 and 4 . The results show a delayed effect of summer heat stress on oocyte quality and embryo development in the autumn. Enhanced removal of the impaired cohort of follicles led to earlier emergence of healthy follicles and high quality oocytes in the autumn.

\section{Introduction}

Low fertility of dairy cattle during the summer in tropical, subtropical and temperate regions is a well-documented event. A less well-known fact is that during the autumn, although the weather is cooler and the cows are no longer subjected to thermal stress, the conception rate remains low (Ron et al., 1984; Badinga et al., 1985). Moreover, the mechanisms by which summer heat stress induces low fertility during the subsequent autumn are not clear.

The susceptibility of oocytes to short-term thermal stress has been documented in both in vitro and in vivo studies. Exposure of fertilized oocytes to increased temperatures had a deleterious effect on early embryonic development (Edwards and Hansen 1996, 1997; Rivera and Hansen, 2001). Exposing heifers to short-term, acute heat stress before artificial insemination increased the number of retarded and abnormal embryos (Putney et al., 1988).

*Correspondence

Email:wolf@agri.huji.ac.il
Seasonal studies have shown that quality of bovine oocytes and rate of embryo development deteriorate in the summer compared with the winter (Rocha et al., 1998; Rutledge et al., 1999), and that the lipid composition of oocyte membranes differs between the seasons (Zeron et al., 2001). However, there have been no published reports of a delayed effect of heat stress on oocyte quality. Roth et al. (2000) showed that exposing cows to thermal stress during one oestrous cycle altered follicular dynamics and attenuated follicular dominance in the subsequent cycle. In another study, in which cows had been exposed to shortterm acute heat stress, medium-sized and preovulatory follicles that had been in early stages of follicular development during the heat exposure showed reduced steroid production several weeks after heat stress had ended (Roth et al., 2001). Thus, exposure of follicles to hyperthermia in the summer, during the early stages of development, may impair oocyte quality and subsequent embryo development during the autumn. Fertility data sets indicate that a period of about 2 months (equivalent to three or four oestrous cycles) is needed for low autumn fertility to 
be restored to the level prevailing in the winter (Ron et al., 1984). We hypothesized that during the autumn, the normal growth and atresia of follicles within the follicular wave dynamics causes slow depletion of the cohort of heat-stressimpaired follicles from the ovaries. Thus, enhanced removal of the pool of impaired follicles should advance the growth of healthy follicles and improve autumn fertility. Enhanced removal could be achieved by transvaginal aspiration of all visible follicles using the ovum pick-up procedure (Pieterse et al., 1988, 1991), which has induced the emergence of a new follicular wave within 1.5-2.0 days (Bergfelt et al., 1994; Garcia and Salaheddine, 1998). Long-term repeated removal (twice a week) of all follicles $>2 \mathrm{~mm}$ in diameter increased the number of follicular waves in cattle (Boni et al., 1997; Garcia and Salaheddine, 1998) without compromising the subsequent cyclicity of the donors (Pieterse et al., 1991; Kruip et al., 1994).

The aims of the present study were: (i) to examine a possible delayed effect of summer heat stress on oocyte quality and embryo development during the autumn; and (ii) to determine whether frequent follicular aspiration improved oocyte quality during the autumn.

\section{Materials and Methods}

\section{Animals}

The experiment was conducted during the autumn (October to November) in the experimental dairy herd of the Agricultural Research Organization in Bet Dagan, Israel; it involved 16 cyclic Holstein lactating cows that had been subjected to thermal stress during the previous summer (June to early October). During the experiment, the cows were fed a complete mixed ration containing $16.5 \%(\mathrm{w} / \mathrm{v})$ protein, 1.7 Mcal $\mathrm{kg}^{-1}$ dry matter and $32 \%(\mathrm{w} / \mathrm{v})$ neutral detergent fibre. Artificial light was supplemented in the barn to obtain $18 \mathrm{~h}$ of light per $24 \mathrm{~h}$, thereby minimizing potential effects of photoperiod. At the beginning of the experiment the cows were, on average, at day 90 after parturition and yielded 35 $\mathrm{kg}$ milk day ${ }^{-1}$. Oestrus was synchronized using an intravaginal device containing progesterone (CIDR; Eazi Breed, Hamilton) and by i.m. injection of PGF $_{2 \alpha}$ analogue $(500 \mu \mathrm{g}$ cloprostenol; Estrumate, Coopers, Berkhamsted). The synchronized cows were assigned randomly to control $(n=8)$ or treatment $(n=8)$ groups.

Air temperature and relative humidity data were obtained from the Central Meteorological Station located $3 \mathrm{~km}$ from the herd. The temperature humidity index (THI) was calculated according to Ingraham et al. (1974): THI = DBT $(0.55-0.55 \times \mathrm{RH})(\mathrm{DBT}-58)$, where DBT is the dry bulb temperature and $\mathrm{RH}$ is the relative humidity. The average daily sums of THI values exceeding 72 ( THI > 72), which is the level generally considered stressful for dairy cattle (Johnson, 1976), were provided by the Meteorological Services. Data on conception rates were obtained from the Israeli herd book. The local ethics committee approved the experiment.

\section{Experimental protocol}

During four consecutive oestrous cycles, all visible follicles $(3-7 \mathrm{~mm}$ in diameter) were aspirated by the transvaginal follicular aspiration procedure (Pieterse et al., 1988). Follicles were aspirated on day 4 of each oestrous cycle in the control group and on days 4, 7, 11 and 15 of each cycle in the treated group, which is of sufficient frequency to prevent the development of dominant follicles (Kruip et al., 1994; Garcia and Salaheddine, 1998). Comparison between experimental groups was made on the basis of oocytes collected on day 4 of each of the four oestrous cycles, before establishment of follicular dominance (Ginther et al., 1996). The same experienced veterinarian performed all follicular aspirations throughout the experiment. PGF $_{2 \alpha}(500 \mu$ g cloprostenol) was injected i.m. on day 19 of each oestrous cycle to regress the corpora lutea and a dose of GnRH analogue $(2.5 \mathrm{ml}$; Receptal; Hoechst, Wiesbaden) was injected i.m. on day 21 (day 0 of the subsequent oestrous cycle) in both groups to induce ovulation of the preovulatory follicle. A 6 day interval between the last aspiration (day 15) and $\mathrm{GnRH}$ injection was sufficient to allow development of a large, dominant, preovulatory follicle in the treated group (Kruip et al., 1994). This experimental design enabled us to synchronize four consecutive oestrous cycles accurately while preserving a normal pattern of growth and regression of corpora lutea and induction of follicular phases, during which preovulatory follicles developed and ovulated in both groups. The follicular dynamics were monitored every 2 days during one representative cycle (cycle 2). Blood samples were collected on days 3, 11, 16, 19 and 20 of cycle 1 and on days 0 , 2, 5, 8, 9, 15, 19 and 20 of cycle 2; the samples were centrifuged at $2000 \mathrm{~g}$ for $20 \mathrm{~min}$ and plasma was stored at $-20^{\circ} \mathrm{C}$ until required.

\section{Follicular aspiration and oocyte collection}

Cows were sedated with $20 \mathrm{mg}$ xylazine i.m. (Rompun $2 \%$, Bayer, Bury St Edmunds) to simplify the manipulation of the cow and the ovary. Caudal epidural anaesthesia was induced with $5 \mathrm{ml}$ of $2 \%(\mathrm{w} / \mathrm{v})$ lidocaine to provide relaxation and analgesia to the rectovaginal region. Follicles were aspirated using an ultrasonic scanner (Pie Medical, Maastricht) and a $7.5 \mathrm{MHz}$ vaginal sector transducer equipped with a needle guide attached to an 18-gauge needle that was connected to a suction pump, set at a flow rate of 25-30 ml min ${ }^{-1}$. For each cow, in each session, follicular contents from all visible follicles $3-7 \mathrm{~mm}$ in diameter were collected into a single $50 \mathrm{ml}$ tube, which contained $5 \mathrm{ml}$ working medium: $10 \mathrm{mmol}$ Hepes-TL solution $\mathrm{I}^{-1}$ (Sigma, St Louis, MO) supplemented with antibiotics (5 $\mu$ g gentamicin $\mathrm{I}^{-1}$; Sigma), $0.2 \mathrm{mmol}$ sodium pyruvate ${ }^{-1}$ (Sigma) and heparin (500 iu per $100 \mathrm{ml}$; Sigma) in $0.4 \%(\mathrm{w} / \mathrm{v}) \mathrm{BSA}$. The tubes containing the aspirated follicular contents were taken immediately to the nearby laboratory for collection of cumulus-oocyte complexes 
(COCs). Recovered COCs were counted, examined morphologically and classified into four categories according to the number of layers of the cumulus surrounding the oocytes and their cytoplasmic consistency, as described elsewhere (De-Loos et al., 1989; Reichenbach et al., 1994): grade 1: spherical, symmetrical and intact oocytes of uniform size, colour and texture, surrounded entirely by three to five compact layers of cumulus cells; grade 2: incomplete COC, partially denuded; grade 3: expanded, denuded, partially degenerated cumulus; and grade 4: totally degenerated COC.

\section{Oocyte maturation and parthenogenetic activation}

Recovered COCs were washed three times with oocyte wash buffer (K-SIWB; Cook, Sydney) and transferred separately for each cow into four-well culture multi-dishes (Nunc, Roskilde) containing $500 \mu \mathrm{l}$ maturation medium: TCM-199 (Sigma) supplemented with 25 mmol Hepes ${ }^{-1}$, supplemented with $0.2 \mathrm{mmol}$ sodium pyruvate $\mathrm{I}^{-1}$ (Sigma), $5 \mu$ gentamicin $\mathrm{I}^{-1}$ (Sigma), 10\% (v/v) heat-inactivated fetal calf serum (FCS; Bio-Lab, Jerusalem,), $10 \mu \mathrm{g}$ ovine $\mathrm{LH} \mathrm{ml} \mathrm{m}^{-1}$ (NIADDK-NIH-26, AFP5551B; Bethesda, MD), $1 \mu \mathrm{g} \mathrm{FSH}$ $\mathrm{ml}^{-1}$ (NIADDK-NIH-20, AFP7028D; Bethesda, MD) and 1 $\mu \mathrm{g}$ oestradiol $\mathrm{ml}^{-1}$, as described elsewhere (Leibfried and First, 1979; Zeron et al., 2001). COCs were incubated for $24 \mathrm{~h}$ at $38.5^{\circ} \mathrm{C}$ in a humidified atmosphere of air containing $5 \% \mathrm{CO}_{2}$. After maturation, cultured oocytes were denuded fully of cumulus cells by pipetting and were activated with ionomycin (Sigma) followed by 6-dimethylaminopurine (Sigma), as described elsewhere (Loi et al., 1998; Zeron et al., 2001). Avoiding the embryo transfer approach in the present study enabled us to use the oocyte activation procedure, with the advantage that embryo development is examined irrespective of the involvement of sperm cells, thereby avoiding fertilization failure that might occur during IVF. In brief, matured oocytes were activated for $5 \mathrm{~min}$ in ionomycin medium: $10 \mathrm{ml}$ TCM-199 supplemented with $25 \mathrm{mmol}$ Hepes $\mathrm{I}^{-1}, 10 \%(\mathrm{v} / \mathrm{v})$ heat-inactivated FCS, $0.2 \mathrm{mmol}$ sodium pyruvate $\mathrm{I}^{-1}, 5 \mu \mathrm{g}$ gentamicin $\mathrm{I}^{-1}$ and $5 \mu \mathrm{g}$ ionomycin $\mathrm{I}^{-1}$ (Sigma). After activation, oocytes were incubated for $4.5 \mathrm{~h}$ with 6-dimethylaminopurine medium $(10 \mathrm{ml}$ TCM-199 supplemented with $2 \mathrm{mmol}$ 6-dimethylaminopurine $\mathrm{I}^{-1}$ ). At the end of incubation, the oocytes were washed three times in a cleavage medium (IVF cleavage medium; Cook), placed into $50 \mu$ l droplets of cleavage medium under mineral oil (Sigma) and incubated for $24 \mathrm{~h}$ at $38.5^{\circ} \mathrm{C}$ and $95 \%$ humidity, in an atmosphere containing $5 \% \mathrm{CO}_{2}$ and $5 \% \mathrm{O}_{2}$. All cleaved embryos were cultured further for 8 days in $50 \mu$ droplets of blastocyst medium (IVF blastocyst medium; Cook) under mineral oil. Oocyte morphology and numbers of cleaved oocytes, fourand eight-cell stage embryos, morulae and parthenogenetic blastocysts were assessed visually once a day during the 8 days of culture. Assessment was carried out separately for each cow in each oestrous cycle.

\section{Progesterone analysis}

Plasma progesterone concentrations were analysed in a single assay with a solid-phase radioimmunoassay kit (Diagnostic Product Corporation, Los Angeles, CA) against a standard curve prepared in our laboratory by dissolving progesterone in ovariectomized cow plasma, as described previously (Schindler et al., 1990; Shaham-Albalancy et al., 2000). Antibody crossreactivity was $0.2 \%$ with $5 \beta$-pregnan$3 \alpha$-ol-20-one and $2 \%$ with $20 \alpha$-dihydroprogesterone. The

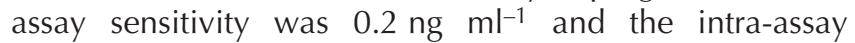
coefficient of variation was $9.8 \%$.

\section{Statistical analysis}

Data on oocyte quality and embryo development collected on day 4 of each oestrous cycle were analysed. The percentages of grade 1 oocytes, cleaved oocytes, fourand eight-cell embryos, morulae and blastocysts from the total number of oocytes recovered were calculated for each cow. In addition, the percentages of morulae and blastocysts from the number of cleaved oocytes were also calculated. As the percentage data did not follow normal distributions, the data were arcsine-transformed before analysis, which was done according to the general linear model procedure of the Statistical Analysis System (SAS, 1987). The statistical model included effects of treatment (treated versus control groups), cows (within treatment) and treatment by cycle interaction. Values are untransformed means \pm SEM.

\section{Results}

Climatic data for summer, autumn and early winter 1998 are shown (Table 1). From June to September, maximum and minimum temperatures, THI values and the accumulated $\mathrm{THI}>72$ units were all indicative of severe summer conditions. Oestrous cycle 1 coincided with the warm weather of early October. Thereafter, during oestrous cycles 2, 3 and 4 (mid-October to early December), the cows were under normothermic conditions, as indicated by the low air temperatures and THI values (Table 1). Conception rates after first insemination, which were lowest (6-13\%) from early August to early October, remained low (20-30\%) in the autumn (late October and November) compared with those in the winter (44\%).

The cows maintained good health, provided their normal milk yield and maintained a relatively good body condition score (2.5 on a scale of 1 to 5$)$ for their stage of lactation and level of milk production during the entire experimental period. No clinical reactions to the repeated transvaginal puncturing of follicles were observed. After oestrous cycle 2, one control cow and one treated cow were excluded from the experiment because of their poor yields of follicles on the day of aspiration. As expected, ultrasonographic monitoring (performed during oestrous cycle 2, data not shown) indicated that, in the treated group, repeated removal (every 3-4 days) of all visible follicles $>3 \mathrm{~mm}$ in 


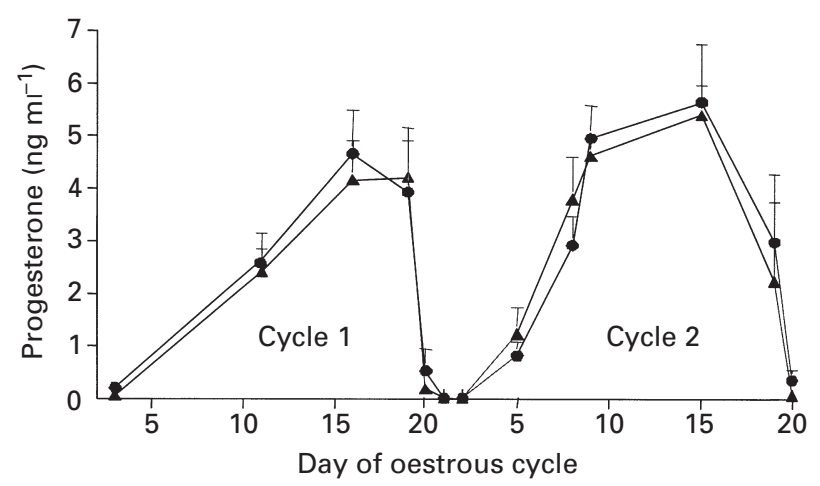

Fig. 1. Plasma concentrations of progesterone in control ( $n=8, \boldsymbol{0}$ and treated $(n=8, \boldsymbol{\Delta})$ cows during two consecutive oestrous cycles. Follicular aspiration was performed on day 4 of the oestrous cycle in the control cows and on days 4, 7, 11 and 15 of the oestrous cycle in the treated cows. $\mathrm{PGF}_{2 \alpha}$ and $\mathrm{GnRH}$ were injected on days 19 and 21, respectively, in both groups. Values are mean \pm SEM

diameter prevented development of dominant follicles between day 0 and day 15 . The numbers of medium-size (6-9 mm) and large (> $10 \mathrm{~mm})$ follicles at the follicular phase (day 19) did not differ between control and treated cows (2.7 and 1.9 versus 2.6 and 1.9, respectively). Progesterone concentrations in the plasma did not differ between oestrous cycle 1 and cycle 2 or between experimental groups (Fig. 1). Similarly, the numbers of corpora lutea did not differ between control and treated cows (1.0 and 1.2, respectively). Control cows showed three follicular waves during the oestrous cycles: the first wave emerged 1-2 days after ovulation (day 0); the second wave emerged 1-2 days after follicular aspiration (performed on day 4); and the third wave emerged on days 11-12 of the cycle. In the treated cows, a total of five waves was induced in each of the experimental oestrous cycles. Similar to control cows, the first wave emerged immediately after ovulation and the remaining waves emerged 1-2 days after each of the follicular aspirations, performed on days 4, 7, 11 and 15 of the oestrous cycle.

The mean numbers of follicles aspirated on day 4 of each oestrous cycle and the numbers and percentages of the oocytes recovered did not differ between control and treated cows (Table 2). In oestrous cycle 1 , the percentages of grade 1 oocytes, cleaved oocytes, eight-cell embryos and blastocysts were low in both groups (Fig. 2a-d). A treatment by cycle interaction $(P<0.05$; Fig. $2 \mathrm{a})$ indicated that there was an earlier increase in the percentage of grade 1 oocytes in the treated cows (cycle 2) than in the control cows (cycle $3)$. The cleavage rate in the treated group increased gradually from about $40 \%$ in cycle 1 to about $75 \%$ in cycles 3 and $4(P<0.05)$, whereas in the control group it fluctuated between $58 \%$ and $32 \%$ during cycles 1 to 4 (Fig. $2 \mathrm{~b})$. This trend was reflected in a treatment by cycle interaction that tended towards significance $(P<0.08)$. The percentages of eight-cell embryos (Fig. 2C) in the control group increased slightly but remained low during the experiment, and the percentages of blastocysts (Fig. 2d) were almost zero, ranging between 1 and $3 \%$. In contrast, significant main effects of treatment and of treatment by cycle interaction indicated marked increases in the percentages of eight-cell embryos in treated cows in cycles 3 and $4(P<0.05)$. Similarly, a significant main effect of treatment on blastocyst formation was detected $(P<0.05)$, reflecting increases in the percentage of blastocysts in treated cows to 10 and $20 \%$ in cycles 3 and 4 , respectively. For comparison, the percentages of blastocysts calculated from cleaved oocytes in the treated group were 14 and $28 \%$ in cycles 3 and 4, respectively. In both control and treated groups, the patterns of change in the percentages of fourcell embryos and morulae during the four cycles were similar to those of eight-cell embryos (Fig. 2c). The mean percentages of four-cell embryos during cycles 1-4 in control and treated cows were $20 \pm 5$ and $50 \pm 9 \%$, respectively $(P<0.05)$. The mean percentages of morulae during cycles 1 to 4 in control and treated cows were $10 \pm 3$ and $30 \pm 6 \%$, respectively $(P<0.05)$.

\section{Discussion}

The present study is the first to show delayed effects of summer heat stress on oocyte quality and embryonic development. Another novel finding is that frequent follicular aspiration enhanced the removal of impaired antral follicles and led to the earlier emergence of healthy follicles and high quality oocytes.

The changes in oocyte quality and embryo development occurring from late summer, throughout the autumn until early winter were expressed in the control group. The low oocyte quality at the end of the summer and early autumn (cycle 1) coincided with moderate heat stress and corresponded well with the low fertility recorded during this period. These findings are consistent with previously reported close associations between long-term summer heat stress (Rocha et al., 1998) or short-term acute heat exposure in vivo or in vitro (Putney et al., 1988; Rivera and Hansen, 2001) and poor embryonic development. However, during the autumn and early winter (cycles 2-4), although the weather was cool, the percentages of grade 1 oocytes increased slightly, but the cleavage rate did not increase and the percentages of four- and eight-cell embryos and morulae remained relatively low, indicating a carry-over effect of previous heat exposure. However, the changes in the control group were not accompanied by an increase in blastocyst development, which remained very low even during early winter (cycle 4), compared with $30 \%$ of blastocysts that developed in the treated group. This finding is surprising, because the delayed effect of summer heat stress in terms of fertility data is, by definition, transient. Indeed, in a similarly designed study using identical methodology, performed a year later under milder summer conditions, a significantly higher percentage of blastocyst development was noted in the early winter than in the autumn (52 versus $11 \%$, respectively; Z. Roth, A. Arav and 
Table 1. Climatic data and conception rates of multiparous cows before, during and after the experimental period, in which follicles were aspirated during four oestrous cycles between early October and early December

\begin{tabular}{|c|c|c|c|c|c|c|c|}
\hline & \multicolumn{2}{|c|}{ Temperature $\left({ }^{\circ} \mathrm{C}\right)$} & \multicolumn{2}{|c|}{ Humidity } & \multirow[b]{2}{*}{ THI maximum } & \multirow[b]{2}{*}{$\mathrm{THI}>72$} & \multirow{2}{*}{$\begin{array}{l}\text { Conception } \\
\text { rate }(\%)\end{array}$} \\
\hline & Minimum & Maximum & Minimum & Maximum & & & \\
\hline June 1998 & 19 & 29 & 54 & 63 & 78 & 10 & 32 \\
\hline July 1998 & 21 & 32 & 50 & 67 & 80 & 23 & 16 \\
\hline August 1998 & 24 & 33 & 55 & 71 & 83 & 36 & 6 \\
\hline September 1998 & 21 & 32 & 49 & 62 & 81 & 21 & 10 \\
\hline 1-15 October 1998 & 18 & 31 & 49 & 65 & 80 & 11 & 13 \\
\hline 16-31 October 1998 & 15 & 27 & 54 & 66 & 73 & 4 & 20 \\
\hline November 1998 & 14 & 25 & 56 & 76 & 72 & 1 & 30 \\
\hline December 1998 & 11 & 21 & 38 & 38 & 66 & 0 & 37 \\
\hline January 1999 & 7 & 19 & 56 & 83 & 64 & 0 & 44 \\
\hline
\end{tabular}

Temperature: mean monthly minimum and maximum air temperatures.

Humidity: mean monthly minimum and maximum relative humidities.

THI: maximum daily temperature humidity index.

THI > 72: daily sum of THI unit $>72$.

Conception rate: conception rates of multiparous cows determined in uncooled herds. Data from Israel Herd Book, based on about 2000 inseminations per month.

Table 2. Numbers of follicles aspirated on day 4 of the oestrous cycles, and numbers and percentages of recovered oocytes in control and treated cows in late summer (cycle 1), autumn (cycles 2-3) and early winter (cycle 4), after exposure to summer heat stress

\begin{tabular}{|c|c|c|c|c|c|c|c|c|c|c|}
\hline & \multicolumn{2}{|c|}{ Cows } & \multicolumn{2}{|c|}{ Aspirated follicles } & \multicolumn{2}{|c|}{ Recovered oocytes } & \multicolumn{2}{|c|}{ Oocytes per cow } & \multicolumn{2}{|c|}{ Recovery (\%) } \\
\hline & Control & Treated & Control & Treated & Control & Treated & Control & Treated & Control & Treated \\
\hline Cycle 1 & 8 & 8 & 56 & 61 & 21 & 23 & 2.6 & 2.9 & 38 & 38 \\
\hline Cycle 2 & 8 & 8 & 78 & 74 & 31 & 28 & 3.9 & 3.5 & 40 & 38 \\
\hline Cycle 3 & 7 & 7 & 71 & 84 & 38 & 41 & 5.4 & 5.9 & 53 & 48 \\
\hline Cycle 4 & 7 & 7 & 72 & 80 & 37 & 40 & 5.3 & 5.7 & 51 & 50 \\
\hline
\end{tabular}

D. Wolfenson, unpublished). It is likely that the exceptionally severe summer conditions in 1998, which extended to early October, prevented blastocyst development in the early winter as well. The above findings indicate that the extent of deterioration of oocyte quality in the autumn and the time needed for recovery of quality may depend on the duration and severity of the thermal stress to which cows were exposed in the previous summer. It is worth noting that the carry-over effect of heat stress on oocyte quality reported and discussed in the present paper could affect not only oocytes that develop in the cool autumn, but also those that develop during the long-term summer heat stress. For example, the limited increase in pregnancy rate achieved through short-term, intensive cooling during the first week after insemination in the summer (Her et al., 1988; Ealy et al., 1994) probably reflects the detrimental effect of heat stress on follicular or oocyte function before the application of cooling.

Studies on heifers and cows have found that impaired oocyte quality in the early postpartum period is associated with a negative energy balance and low body condition (Kendrick et al., 1999; Snijders et al., 2000). It has been claimed that a postpartum period of about 90 days is needed to obtain high quality oocytes (O'Callaghan et al., 1999; Gwazdauskas et al., 2000). It was necessary to eliminate the possibility that the impairment of oocyte quality was associated with the metabolic status of the cows examined to confirm that the impairment of oocyte quality in the autumn, documented in the present study, resulted from previous exposure to summer heat stress. Accordingly, the cows were at day 90 after parturition at the beginning of the present study to exclude possible postpartum effects, and maintained a relatively good body condition score. Cows at this stage of lactation are cyclic and usually maintain a positive energy balance (Moallem et al., 1999). Furthermore, in contrast to the findings in the present study, it has been found that during the winter, cows at days 70-150 after parturition yielded high rates of grade 1 oocytes and blastocysts (78 and 45\%, respectively; G. Inbar, D. Wolfenson and A. Arav, unpublished). Furthermore, the possibility that exposure of cows to thermal stress in the summer impaired their metabolic status and lowered the postpartum body condition more in the autumn than in other seasons can also be eliminated. For example, in largescale seasonal surveys of high-yielding dairy cows in Israel (Reches et al., 2000) and in a study on lactating cows in 

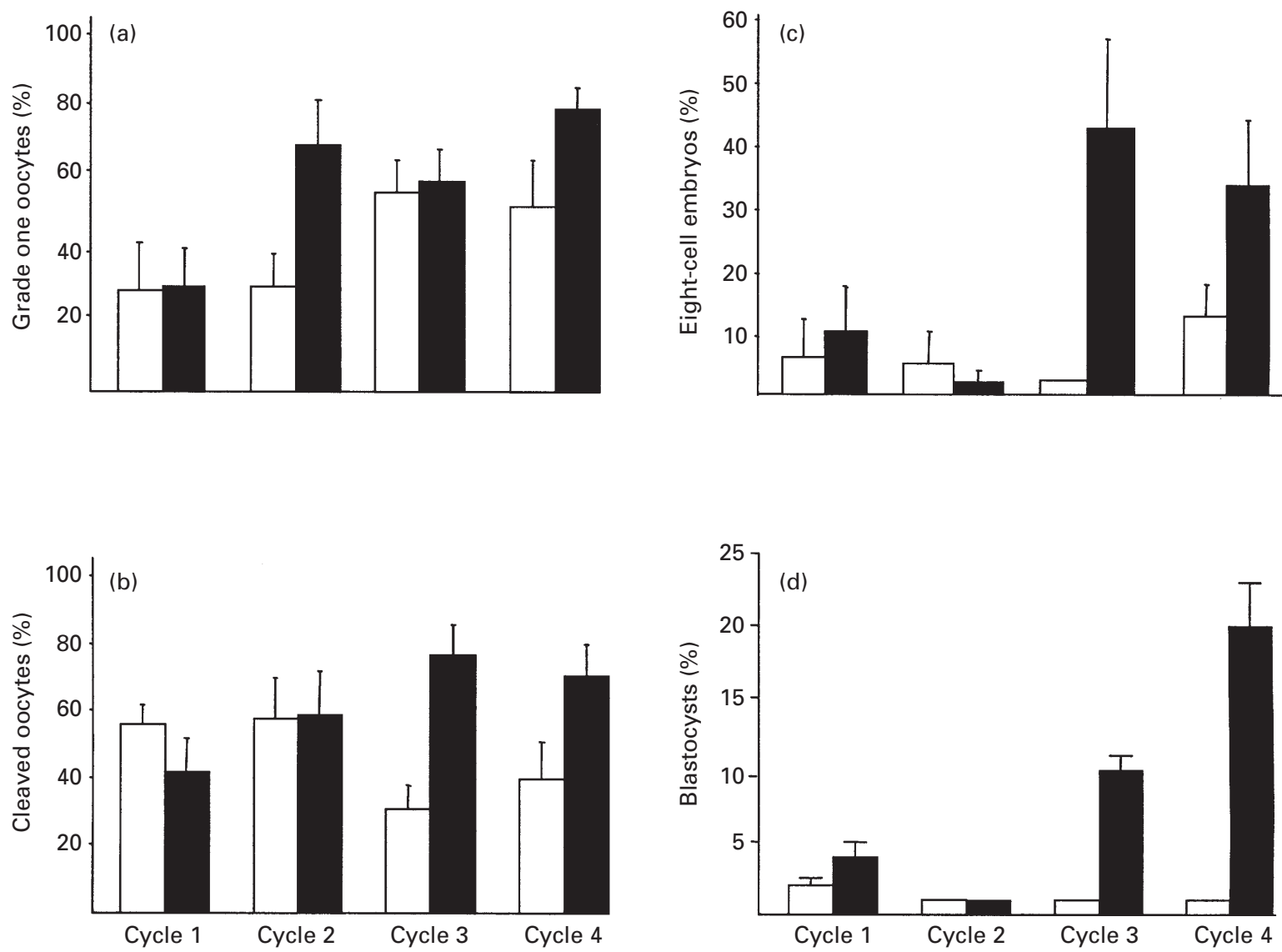

Fig. 2. Percentages of (a) grade 1 oocytes, (b) cleaved oocytes, (c) eight-cell embryos and (d) blastocysts, calculated from recovered oocytes, in control $(n=7-8, \square)$ and treated $(n=7-8, \mathbf{\square})$ cows. Follicular aspiration was performed on day 4 of the oestrous cycle in the control cows and on days 4, 7, 11 and 15 of the oestrous cycle in the treated cows. PGF $2 \alpha$ and GnRH were injected on days 19 and 21, respectively, in both groups. Oocytes were recovered on day 4 of four consecutive oestrous cycles in late summer (cycle 1), autumn (cycles 2 and 3) and early winter (cycle 4), after exposure to summer heat stress. A treatment by cycle interaction was detected for grade 1 oocytes $(P<0.05)$. Cleavage rates differ between treatments in cycles 3 and $4(P<0.05)$. A main effect of treatment and a treatment by cycle interaction were detected for eight-cell embryos $(P<0.05)$. A main effect of treatment was detected for blastocysts $(P<0.05)$. Values are mean \pm SEM.

Australia (Jonsson et al., 1997), no differences in body condition scores at calving or after parturition were detected between cows calving in summer and in winter. Collectively, the above findings indicate that the poor oocyte quality and embryo development in the autumn, as recorded in the present study, resulted from the hyperthermia induced during the previous exposure to summer heat. It is less likely that alteration in metabolic status or of stage of lactation after parturition are involved in low oocyte quality.

Oocytes are susceptible to thermal stress (Edwards and Hansen, 1997; Rivera and Hansen, 2001), but the mechanism by which heat stress impairs oocyte quality is less clear. Oocyte membrane characteristics, such as fatty acid composition, and physical properties such as lipid phase transition, are altered by exposure to low temperatures or to high temperatures during long-term summer heat stress (Arav et al., 1996; Zeron et al., 2001). However, it is not known whether such cellular changes persist from the summer into the autumn. Roth et al. (2001) found that a delayed effect of heat stress on steroidogenesis in thecal and granulosa cells was related to previous exposure of antral follicles of about $0.5-1.0 \mathrm{~mm}$ in diameter to thermal stress. At such an early antral stage of follicular development, bovine oocytes are still in the growth phase, which is characterized by intensive RNA synthesis (Fair et al., 1995, 1996) and might be particularly sensitive to environmental changes. Another possibility is impairment of cell-cell communication between granulosa and cumulus cells, and between cumulus and oocyte, which might impair oocyte competence. In addition, the delayed impairment of oocyte function in heat-stressed cattle may result from alteration in the contents of follicular fluids such as insulin-like growth factor binding proteins (IGFBPs; Ambrose et al., 1999) or steroids (Wolfenson et al., 1997). A delayed deleterious effect of heat exposure on steroidogenesis of thecal and 
granulosa cells has been recorded, which corresponded to decreased follicular fluid oestradiol concentrations in the autumn (Roth et al., 2001). Such a decrease may affect secretion of gonadotrophins and could be involved in alteration of acquisition of meiotic competence.

The frequent follicular aspiration to which the treated group was subjected in the present study induced an earlier recovery of oocyte quality in the autumn. Such improvement probably resulted from enhanced removal of a pool of follicles that had been damaged in the previous summer. Bovine ovaries contain about 250 very small antral follicles measuring 0.6-0.9 mm in diameter (Miyamura et al., 1996). In our previous study, this stage of folliculogenesis was hypothesized to be susceptible to heat stress (Roth et al., 2001). Thus, it could be assumed that long-term exposure to summer heat stress during the early stages of follicular development had impaired this pool of small antral follicles that, nevertheless, continued to grow to $3-7 \mathrm{~mm}$ in diameter and were aspirated during the autumn. This transient pool of damaged follicles, which emerged during the autumn, would be removed naturally from the ovaries during three to four consecutive cycles, as occurred in the control group; their removal was also reflected in the fertility data. However, the frequent follicular aspirations performed in the present study induced the emergence of two extra follicular waves per cycle in the treated cows (a total of eight extra follicular waves during the entire experiment). An average follicular wave comprises about 24 small (3-4 mm in diameter) antral follicles (Ginther et al., 1996); therefore, it is estimated that in the present study about 200 more follicles emerged and were removed in the treated group than in the control group. This estimate does not differ greatly from the figures presented by Miyamura et al. (1996).

Frequent follicular aspiration per se is less likely to improve oocyte quality, irrespective of the removal of a pool of defective follicles, as suggested above, for the following reasons. Firstly, in the present study, frequent follicular aspiration performed in cycle 1 failed to improve any stage of embryo development in the treated cows (cleavage, four- and eight-cell embryos, morulae or blastocysts) during the subsequent cycle (cycle 2); improvement was evident only later, in cycles 3 and 4, after aspiration of additional impaired follicles. Secondly, experiments that were not associated with heat stress conditions, unlike the present study, have shown that oocytes of high quality at the beginning of various studies were unaffected by long-term, frequent follicular aspiration (Kruip et al., 1994; Bols et al., 1998); sometimes the percentage of developed embryos decreased over time (Kruip et al., 1995). Thirdly, other studies have found that twice-weekly follicular aspiration led to more viable oocytes than did once-weekly aspiration, and that the increase was associated with the elimination of dominance and the aspiration of small follicles rather than mediumsized follicles that may already be degenerating when collected under a once-weekly protocol (Garcia and
Salaheddine, 1998; Goodhand et al., 1999). However, in the present study, although follicular aspiration in the treated group was performed twice a week compared with once per cycle in the control group, the comparison between treated and control groups was valid as oocyte quality was assessed on day 4 of each cycle in both treated and control groups, before the onset of any detrimental effect of the first-wave dominant follicle on the subordinate follicles. Furthermore, aspiration on day 4 of each cycle was performed in both control and treated groups, both of which had followed similarly normal patterns of growth and regression of corpora lutea, induction of follicular phases, growth of dominant preovulatory follicles and ovulation in the previous cycles. Collectively, these factors indicate that frequent follicular aspiration did not have any beneficial effect on oocyte quality in the treated cows, other than faster removal of defective follicles from the ovary. However, despite the points discussed above, it could be argued that the pool of follicles that were aspirated on day 4 of the cycle might have been influenced by an extensive period of less follicular dominance during the previous cycle. Additional examination of the effect of frequent follicular aspiration on oocyte quality should be performed during the winter on cows that had not been exposed to heat stress during the preceding season to clarify this matter further.

In conclusion, the present study provides clear evidence for a delayed effect of summer heat stress on oocyte quality. Enhanced removal of the impaired cohort of follicles during the autumn led to earlier emergence of healthy follicles and higher quality oocytes. Hormonal treatment that would enhance the emergence of more follicles or induce more follicular waves could improve autumn fertility of cows in warm climates.

The authors would like to thank A. Ocheretny for her technical assistance and NIADDK-NIH for provision of $\mathrm{LH}$ and FSH.

\section{References}

Ambrose JD, Guzeloglu A, Thatcher MJ, Kassa T, Diaz T and Thatcher WW (1999) Long-term follicular dynamics and biochemical characteristics of dominant follicles in dairy cows subjected to heat-stress Journal of Reproduction and Fertility Supplement 54 503-504 (Abstract)

Arav A, Zeron Y, Leslie SB, Behboodi E, Anderson GB and Crowe JH (1996) Phase transition temperature and chilling sensitivity of bovine oocytes Cryobiology 33 589-599

Badinga L, Collier RJ, Thatcher WW and Wilcox CJ (1985) Effects of climatic and management factors on conception rate of dairy cattle in subtropical environment Journal of Dairy Science 68 78-85

Bergfelt DR, Lightfoot KC and Adams GP (1994) Ovarian synchronization following ultrasound-guided transvaginal follicle ablation in cyclic heifers Theriogenology 42 895-907

Bols PEJ, Ysebaert MT, Lein A, Coryn M, Van Soon A and de Kruif A (1998) Effect of long-term treatment with bovine somatotropin on follicular dynamics and subsequent oocyte and blastocyst yield in an OPU-IVF program Theriogenology 49 983-995

Boni R, Roelofsen MWM, Pieterse MC, Kogut J and Kruip ThAM (1997) Follicular dynamics repeatability and predictability of follicular recruitment in cows undergoing repeated follicular puncture Theriogenology 48 277-289 
De-Loos F, Van-Vliet C, Van Maurik P and Kruip ThAM (1989) Morphology of immature bovine oocytes Gamete Research 24 197-204

Ealy AD, Arechiga CF, Bary DR, Risco CA and Hansen PJ (1994) Effectiveness of short-term cooling and vitamin $E$ for alleviation of infertility induced by heat stress in dairy cows Journal of Dairy Science $773601-3607$

Edwards JL and Hansen PJ (1996) Elevated temperature increases heat shock protein 70 in bovine two-cell embryos and compromises function of maturing oocytes Biology of Reproduction 55 340-346

Edwards JL and Hansen PJ (1997) Differential responses of bovine oocytes and preimplantation embryos to heat shock Molecular Reproduction and Development 46 138-145

Fair T, Hyttel P and Greve T (1995) Bovine oocyte diameter in relation to maturational competence and transcriptional activity Molecular Reproduction and Development 42 437-442

Fair T, Hyttel P, Greve T and Boland M (1996) Nucleus structure and transcriptional activity in relation to oocyte diameter in cattle Molecular Reproduction and Development 43 503-512

Garcia A and Salaheddine M (1998) Effect of repeated ultrasound-guided transvaginal follicular aspiration on bovine oocyte recovery and subsequent follicular development Theriogenology 50 575-585

Ginther OJ, Wiltbank MC, Fricke PM, Gibbons JR and Kot K (1996) Selection of the dominant follicle in cattle Biology of Reproduction $\mathbf{5 5}$ 1187-1194

Goodhand KL, Watt RG, Staines ME, Hutchinson JSM and Broadbent PJ (1999) In vivo oocyte recovery and in vitro embryo production from bovine donors aspirated at different frequencies or following $\mathrm{FSH}$ treatment Theriogenology 51 951-961

Gwazdauskas FC, Kendrick KW, Pryor AW and Baily TL (2000) Impact of follicular aspiration on folliculogenesis as influenced by dietary energy and stage of lactation Journal of Dairy Science 83 1625-1634

Her E, Wolfenson D, Flamenbaum I, Folman Y, Kaim M and Berman A (1988) Thermal productive, and reproductive responses of high yielding cows exposed to short term cooling in summer Journal of Dairy Science 71 1085-1092

Ingraham RH, Gillette DD and Wagner WD (1974) Relationship of temperature and humidity to conception rate of Holstein cows in subtropical climate Journal of Dairy Science 57 476-482

Johnson HD (1976) World climate and milk production Journal of Biometeorology 20 171-180

Jonsson NN, McGowan MR, McGuigan K, Davison TM, Hussain AM, Kafi M and Matschoss A (1997) Relationships among calving season, heat load, energy balance and postpartum ovulation of dairy cows in a subtropical environment Animal Reproduction Science 47 315-326

Kendrick KW, Bailey TL, Garst AS, Pryor AW, Ahmadzadeh A, Akers RM, Eyestone WE, Pearson RE and Gwazdauskas FC (1999) Effect of energy balance on hormones, ovarian activity, and recovered oocytes in lactating Holstein cows using transvaginal follicular aspiration Journal of Dairy Science 82 1731-1740

Kruip ThAM, Boni R, Wurth YA, Roelofsen MWM and Pieterse MC (1994) Potential use of ovum pick-up for embryo production and breeding in cattle Theriogenology 40 675-684

Kruip ThAM, Van Beek H, De Wit A and Postma A (1995) Quality of bovine oocytes in dairy cows post partum: consequences for embryo production in vivo and in vitro. Proceedings of the $11^{\text {th }}$ Meeting of the European Embryo Transfer Association 113-119

Leibfried L and First NL (1979) Characterization of bovine follicular oocytes and their ability to mature in vitro. Journal of Animal Science 53 76-86

Loi P, Ledda S, Fulka JR, Cappai P and Moor RM (1998) Development of parthenogenetic and cloned ovine embryos: effect of activation protocol Biology of Reproduction 58 1177-1187

Miyamura M, Kuwayama M, Hamawaki A and Eguchil Y (1996) Total number of follicles in the ovaries of Japanese Black cattle Theriogenology 45300 (Abstract)

Moallem U, Folman Y, Bor A, Arav A and Sklen D (1999) Effect of calcium soaps of fatty acids administration of somatotropin on milk production, preovulatory follicular development, and plasma and follicular fluid lipid composition in high yielding dairy cows Journal of Dairy Science 82 2358-2368

O'Callaghan D, Lozano JM, Fahey J, Gath V, Snijders S and Boland MP (1999) Endocrine and metabolic effects of nutrition on fertility Occasional Meeting, British Society of Animal Science, Galway 15-16 (Abstract)

Pieterse MC, Kappen KA, Kruip ThAM and Taverne MAM (1988) Aspiration of bovine oocytes during transvaginal ultrasound scanning of the ovaries Theriogenology 30 751-762

Pieterse MC, Vos PLAM, Kruip ThAM, Wurth YA, van Beneden ThH Willemse AH and Taverne MAM (1991) Characteristics of bovine estrous cycle during repeated transvaginal ultrasound-guided puncturing of follicles for ovum pick-up Theriogenology 35 401-413

Putney DJ, Drost M and Thatcher WW (1988) Embryonic development in superovulated dairy cattle exposed to elevated ambient temperatures between days 1 to 7 post insemination Theriogenology 30 195-209

Reches M, Flamenbaum I and Ezra E (2000) Characterization of body condition of dairy cows during the dry period and at parturition and its relation to milk production in the subsequent lactation 12th Annual Meeting of the Israeli Dairy Production Conference Caesarea 12-13 (in Hebrew) (Abstract)

Reichenbach HD, Wiebke NH, Wenigerkind H, ModI J and Brem G (1994) Bovine follicular oocyte collected by laparoscopic guided transvaginal aspiration Theriogenology 41283 (Abstract)

Rivera RM and Hansen PJ (2001) Development of cultured bovine embryos after exposure to high temperatures in the physiological range Reproduction 121 107-115

Rocha A, Randel RD, Broussard JR, Lim JM, Blair RM, Roussel JD, Godke RA and Hansel W (1998) High environmental temperature and humidity decrease oocyte quality in Bos taurus but not in Bos indicus cows Theriogenology 49 657-665

Ron M, Bar-Anan R and Wiggans GR (1984) Factors affecting conception rate of Israeli Holstein cows Journal of Dairy Science 67 854-860

Roth Z, Meidan R, Braw-Tal R and Wolfenson D (2000) Immediate and delayed effects of heat stress on follicular development and its association with plasma FSH and inhibin concentration in cows Journal of Reproduction and Fertility 120 83-90

Roth Z, Meidan R, Shaham-Albalancy A, Braw-Tal R and Wolfenson D (2001) Delayed effect of heat stress on steroid production in mediumsized and preovulatory bovine follicles Reproduction 121 745-751

Rutledge JJ, Monson RL, Northey DL and Leibfried-Rutledge ML (1999) Seasonality of cattle embryo production in a temperate region Theriogenology 51330 (Abstract)

SAS Inc (1987) SAS User's Guide $6^{\text {th }}$ Edn. SAS Institute Inc., Cary, NC

Schindler D, Lewis GS, Rosenberg M, Tadmor A, Ezov N, Ron M, Eizinbud E and Lehrer AR (1990) Vulvar electrical impedance in periparturient cows and its relation to plasma progesterone, oestradiol-17 $\beta$ and PGFM Animal Reproduction Science 23 283-292

Shaham-Albalancy A, Rosenberg M, Folman Y, Graber Y, Meidan R and Wolfenson D (2000) Two methods of inducing low plasma progesterone concentrations have different effects on dominant follicles in cows Journal of Dairy Science 83 2771-2778

Snijders SE, Dillon P, O'Callaghan D and Boland MP (2000) Effect of genetic merit, milk yield, body condition and lactating number on in vitro oocyte development in dairy cows Theriogenology 53 981-989

Wolfenson D, Lew BJ, Thatcher WW, Graber Y and Meidan R (1997) Seasonal and acute heat stress effects on steroid production by dominant follicles in cows Animal Reproduction Science 47 9-19

Zeron Y, Ocheretny A, Kedar O, Borochov A, Sklan D and Arav A (2001) Seasonal changes in bovine fertility: relation to oocyte developmental competence, membrane properties and follicle fatty acid composition Reproduction $121447-454$

Received 9 April 2001.

First decision 22 May 2001.

Accepted 4 July 2001. 